\title{
Serum Levels of TNF- $\alpha$, IFN- $\gamma$, IL-6, IL-8, IL-12, IL-17, and IL-18 in Patients With Active Psoriasis and Correlation With Disease Severity
}

\author{
Ozer Arican, ${ }^{1}$ Murat Aral, ${ }^{2}$ Sezai Sasmaz, ${ }^{1}$ and Pinar Ciragil ${ }^{2}$ \\ ${ }^{1}$ Department of Dermatology, Faculty of Medicine, Kahramanmaras Sutcu Imam University, Kahramanmaras 46000, Turkey \\ ${ }^{2}$ Department of Microbiology, Faculty of Medicine, Kahramanmaras Sutcu Imam University, Kahramanmaras 46000, Turkey
}

Received 6 June 2005; accepted 27 June 2005

\begin{abstract}
Recent progress in the understanding of psoriasis has shown that the regulation of local and systemic cytokines plays an important role in its pathogenesis. The most often used psoriasis score is the psoriasis area and severity index (PASI). A simple laboratory test from a blood sample would be an attractive, patient-independent, and observer-independent marker of disease severity. To this end, we evaluated the association of serum levels of some proinflammatory cytokines in vivo and their correlation with severity of psoriasis. The serum levels of cytokines levels were determined with the use of the ELISA method. All mean values except IL-17 levels of patients were significantly higher than those of controls. There was a significant correlation between serum levels of IFN- $\gamma$, IL-12, IL-17, and IL-18, and severity of the disease. Psoriasis can be described as a T-cell-mediated disease, with a complex role for a variety of cytokines, which has led to the development of new immunomodulatory therapies. In this study, serum TNF- $\alpha$, IFN- $\gamma$, IL-6, IL-8, IL-12, and IL-18 levels were significantly higher in active psoriatic patients than in controls. Furthermore, high levels of IFN- $\gamma$, IL-12, and IL-18 correlated with the clinical severity and activity of psoriasis, and those measurements of serum levels of these cytokines may be objective parameters for the disease severity.
\end{abstract}

\section{INTRODUCTION}

Psoriasis, a common and enigmatic recurrent cutaneous disease, has for long been considered a hyperproliferation with extremelyincreased rate of epidermal turnover, and an activated mononuclear infiltrate in the underlyingdermis. Recent progress in the understanding of psoriasis has attributed its pathogenesis to the important role of $\mathrm{T}$ cells. New anti-T lymphocytes immunotherapies, and some traditional antipsoriatic medications such as methotrexate,steroids, and cyclosporin A, have confirmed an important role of the immune system in psoriasis [1]. At present, research into psoriasis is dominated by thehypothesis that it is an immunological disorder described by abnormal keratinocyte proliferation mediated through T lymphocytes [2, 3, 4]. Autoimmune disorders and inflammatory reactions are currently segregated into cell-mediated Th1 or Th2 categories. Psoriasis is associated with an overexpression of proinflammatory cytokines produced by Th1 cells and relative un-

Correspondence and reprint requests to Ozer Arican, Department of Dermatology, Faculty of Medicine, Kahramanmaras Sutcu Imam University, Kahramanmaras 46000, Turkey; ozerari@hotmail.com; ozerari@gmail.com derexpression of Th2 cytokines [5]. Today,the roles of cytokines in the pathogenesis of psoriasis are investigated. However, in extrapolating the biologic these activities of cytokines demonstrated in the in vitro models to the in vivo situation in psoriasis, it is clear that there may be much more complex interactions among individual cytokines in vivo than expected from the in vitro models.

There does not yet exist an objective laboratory parameter to measure the severity of psoriasis. Th1 cytokines are found in high levels both in lesional skin and in the peripheral blood in the psoriatic patients. Serum is easy to obtain from patients and small amounts of it will be sufficient. Thus, the measurement of serum cytokines may allow for better monitoring and prediction of disease severity. In this study, we evaluated association with serum levels of some proinflammatory cytokines (IFN$\gamma$, TNF- $\alpha$, IL-6, IL-8, IL-12, IL-17, and IL-18) and their correlation with severity of psoriasis in Turkish population. With the understanding of relationships between cytokines, it could be possible to describe the pathogenesis of the disease. In cases that are difficult to diagnose, and also in the follow-up of the patients, the assessment of these different parameters in the peripheral blood at the same time may be of use. Therefore, we also evaluated in vivo relationships of these cytokines. 
TABLE 1. Mean, minimum-maximum, and median values of serum cytokines levels in psoriatic patients and healthy controls, and the results of statistical assessments. Values are mean \pm SD.

\begin{tabular}{cccc}
\hline Cytokines & $\begin{array}{c}\text { Patients } \\
(n=30)\end{array}$ & $\begin{array}{c}\text { Controls } \\
(n=23)\end{array}$ & $P$ \\
\hline IFN- $\gamma(\mathrm{IU} / \mathrm{mL})$ & $0.95 \pm 0.907(0.0-3.1,0.7)$ & $0.42 \pm 0.465(0.0-1.5,0.3)$ & $<.05^{*}$ \\
TNF- $\alpha(\mathrm{pg} / \mathrm{mL})$ & $25.7 \pm 10.62(4.8-44.6,23.4)$ & $11.2 \pm 7.31(0.0-32.5,11.3)$ & $<.001^{* *}$ \\
IL-6 $(\mathrm{pg} / \mathrm{mL})$ & $13.7 \pm 12.18(0.0-62.0,12.6)$ & $4.2 \pm 5.86(0.0-12.7,0.0)$ & $<.001^{*}$ \\
IL-8 $(\mathrm{pg} / \mathrm{mL})$ & $35.9 \pm 22.77(2.8-80.9,38.4)$ & $12.9 \pm 13.93(0.0-50.4,7.9)$ & $<.001^{* *}$ \\
IL-12 $(\mathrm{pg} / \mathrm{mL})$ & $36.6 \pm 17.93(2.9-62.4,33.8)$ & $24.9 \pm 13.29(2.9-53.9,25.8)$ & $<.001^{* *}$ \\
IL-17 $(\mathrm{pg} / \mathrm{mL})$ & $8.3 \pm 3.80(0.0-13.9,6.2)$ & $7.4 \pm 3.76(0.0-13.4,6.2)$ & $>.05^{*}$ \\
IL-18 $(\mathrm{pg} / \mathrm{mL})$ & $88.6 \pm 36.81(0.0-124.8,101.9)$ & $32.7 \pm 19.39(0.0-70.0,26.6)$ & $<.001^{*}$ \\
\hline
\end{tabular}

*Mann-Whitney $U$ test, ${ }^{* *}$ Student $t$ test.

\section{MATERIALS AND METHODS}

\section{Patients and controls}

Consecutive patients with psoriasis who had not received any prior local or systemic treatment within two months were included in the study. The diagnosis was made clinically, based on characteristic plaque-type psoriatic lesions. Patients with erythrodermic, pustular, and only palmoplantar forms of psoriasis, and patients with psoriatic arthritis were excluded. The severity of psoriasis was assessed by the psoriasis area and severity index (PASI) for each patient. The control group was comprised of healthy, nonpsoriatic volunteers with no family history of psoriasis. Blood, urine, and feces specimens were collected from both patients and controls for routine laboratory investigations including blood sedimentation rate, liver enzymes, blood cell counts, and C-reactive protein level to exclude organic or metabolic abnormalities and infections at the same time points. A signed informed consent was taken from all patients and controls.

\section{Serum}

Venous blood samples $(5-10 \mathrm{~mL})$ were taken in vacutainer tubes under sterile conditions from patients and controls between 08:30-10:30 am. Serum was obtained from freshly drawn, rapidly centrifugated. Serum was quickly frozen at $-70^{\circ} \mathrm{C}$ and stored until processed.

\section{Cytokines detections}

Serum TNF- $\alpha$, IFN- $\gamma$, IL-6, IL-8, IL-12 (p40 kit), IL17 , and IL-18 levels were measured by enzyme-linked immunosorbent assay (ELISA) technique (enzyme-amplified sensitivity immunoassay (EASIA) kits, BioSource Europe SA, 8 B-1400, Nivelles, Belgium). These assays detected only human cytokines and the minimum detectable concentrations in our laboratory were $4.8 \mathrm{pg} / \mathrm{mL}$ for TNF- $\alpha, 0.2 \mathrm{IU} / \mathrm{mL}$ for IFN- $\gamma, 1.1 \mathrm{pg} / \mathrm{mL}$ for IL- 6 , $1.9 \mathrm{pg} / \mathrm{mL}$ for IL-8, $2.9 \mathrm{pg} / \mathrm{mL}$ for IL-12, $4.6 \mathrm{pg} / \mathrm{mL}$ for IL17 , and $16.6 \mathrm{pg} / \mathrm{mL}$ for IL-18.

\section{Statistical analyses}

All data were analyzed using the statistical package for social science (SPSS) 10.0 for Windows program on the computer. All data were given as mean \pm standard deviation (SD). Chi-square test was used to compare differences between the frequencies. Serum cytokines levels were analyzed using the normality test. The MannWhitney $U$ and Student $t$ test was used to compare mean values between groups. Spearman rank correlation test was used for the assessment of correlation. The statistical significance was accepted as $P$ value $<0.05$.

\section{RESULTS}

A total of 30 patients (18 males, 12 females), of mean age $35 \pm 15.5$ (range: 7-79) years, and 23 ageand sex-matched healthy controls were enrolled in this study. There were no significant differences in age and male/female ratio between the patients and controls $(P>$ $0.05)$. Neither patients nor controls had a history of, or clinical or routine laboratory findings consistent with, impaired hepatic or renal function, nor parasitic or any other infection. The cell counts in whole blood and C-reactive protein levels were in normal ranges in each patient and controls. The mean duration of illness for the patients group was $9 \pm 10.1$ (range: $1-40$ ) years. The average PASI score in patients was $9.3 \pm 8.15$ (range: $1.5-33.3$ ).

The mean, minimum, maximum, and median values of the serum levels of interleukins, TNF- $\alpha$, and IFN- $\gamma$ of both groups and statistical results are presented in Table 1. The results also are shown in Figures 1a, 1b, 1c, 1d, 1e, and 1f. All mean values except IL-17 levels of patients were significantly higher than those of controls. There was correlation between serum levels of IFN- $\gamma$, IL-12, IL-17, and IL-18, and severity of the disease. Correlation among disease severity and serum levels of cytokines are shown in Table 2.

In healthy controls, there were no correlations among the serum levels of TNF- $\alpha$, IFN- $\gamma$ IL-6, IL-8, IL-12, IL-17, and IL-18. There was no correlation between age or gender and serum cytokines levels in both groups. 


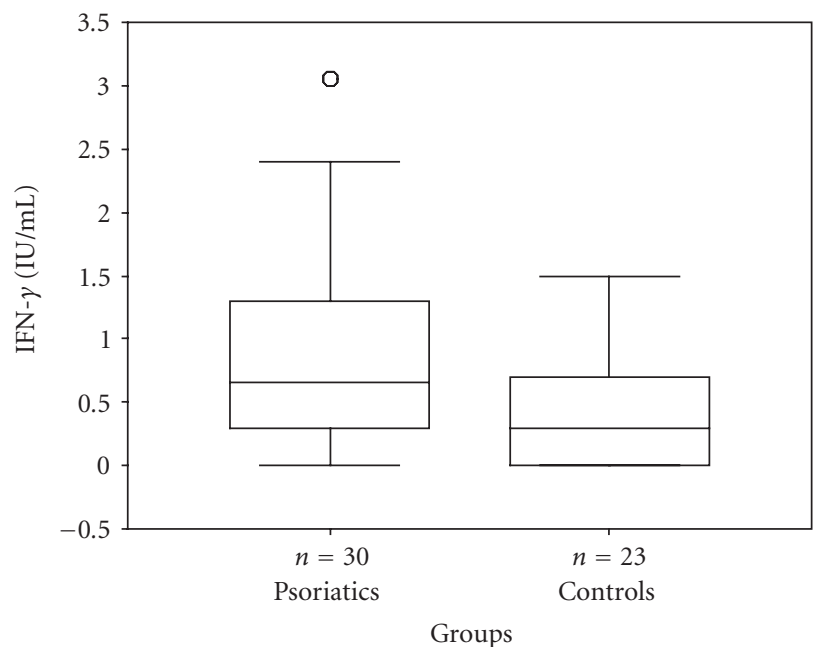

(a)

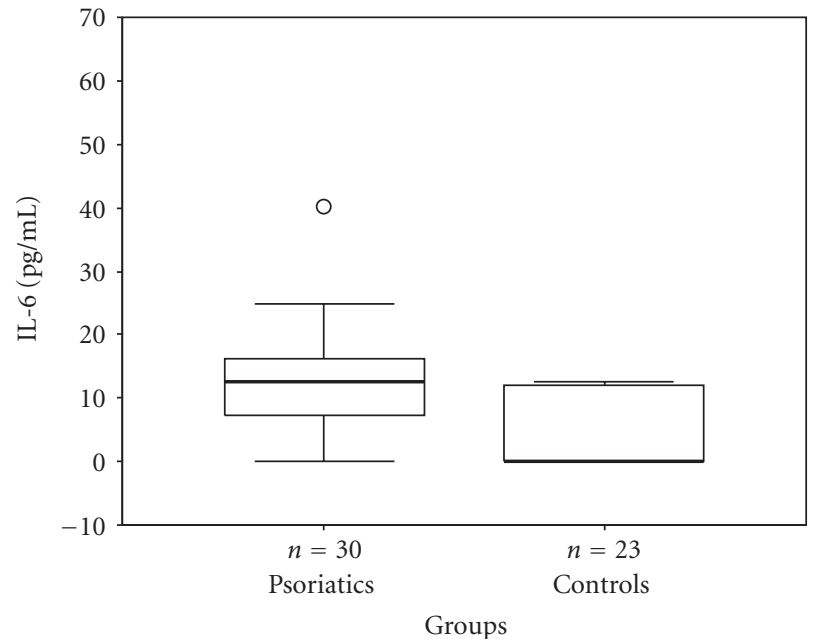

(c)



(e)



(b)

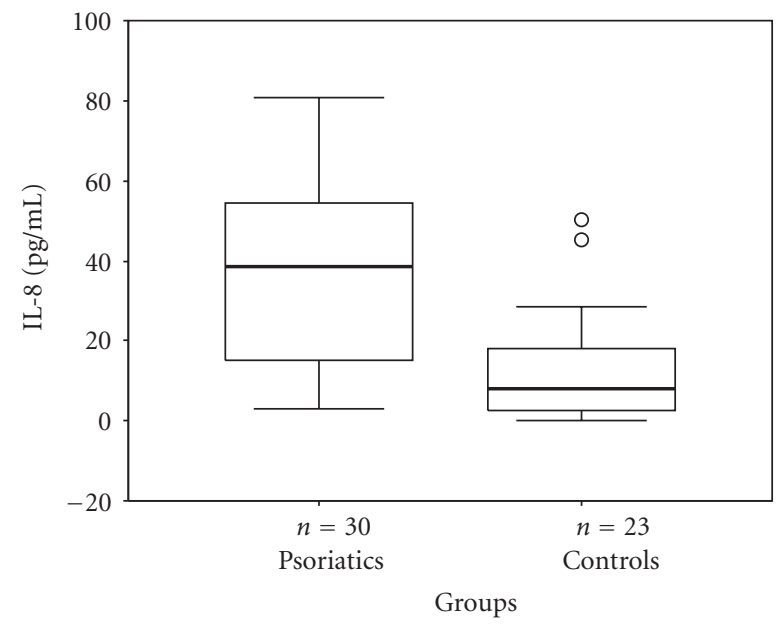

(d)



(f)

Figure 1. (a) IFN- $\gamma$, (b) TNF- $\alpha$, (c) IL-6, (d) IL-8, (e) IL-12, and (f) IL-18 serum levels of psoriatic patients and controls in box plot graphics ( $\mathrm{O}$ : outliers). 
TABLE 2. Correlation among disease severities and serum cytokines levels evaluated by the Spearman rank correlation.

\begin{tabular}{|c|c|c|c|c|c|c|c|c|}
\hline PASI and cytokines & Statistical values & IFN- $\gamma$ & TNF- $\alpha$ & IL-6 & IL-8 & IL-12 & IL-17 & IL-18 \\
\hline \multirow{2}{*}{ PASI } & $r$ & 0.89 & -0.29 & 0.03 & -0.06 & 0.93 & 0.47 & 0.86 \\
\hline & $P$ & 0.00 & 0.12 & 0.88 & 0.75 & 0.00 & 0.01 & 0.00 \\
\hline \multirow{2}{*}{ IFN- $\gamma$} & $r$ & - & -0.18 & 0.08 & 0.04 & 0.88 & 0.38 & 0.78 \\
\hline & $P$ & - & 0.35 & 0.67 & 0.82 & 0.00 & 0.04 & 0.00 \\
\hline \multirow{2}{*}{ TNF- $\alpha$} & $r$ & - & - & -0.16 & 0.18 & -0.22 & 0.12 & -0.10 \\
\hline & $P$ & - & - & 0.39 & 0.33 & 0.24 & 0.52 & 0.60 \\
\hline \multirow{2}{*}{ IL-6 } & $r$ & - & - & - & -0.05 & -0.10 & 0.21 & 0.05 \\
\hline & $P$ & - & - & - & 0.80 & 0.58 & 0.27 & 0.82 \\
\hline \multirow{2}{*}{ IL-8 } & $r$ & - & - & - & - & -0.02 & -0.02 & -0.09 \\
\hline & $P$ & - & - & - & - & 0.94 & 0.90 & 0.65 \\
\hline \multirow{2}{*}{ IL-12 } & $r$ & - & - & - & - & - & 0.43 & 0.90 \\
\hline & $P$ & - & - & - & - & - & 0.02 & 0.00 \\
\hline \multirow{2}{*}{ IL-17 } & $r$ & - & - & - & - & - & - & 0.72 \\
\hline & $P$ & - & - & - & - & - & - & 0.00 \\
\hline
\end{tabular}

\section{CONCLUSION}

Histologically, psoriasis is characterized by marked keratinocyte hyperproliferation, a dense inflammatory infiltrate consisting of T cells and neutrophils, and vascular dilatation and proliferation. The primary defect in psoriasis patients was believed to be abnormal epidermal cells proliferation [6]. The very early lesion of psoriasis is characterized by an inflammatory infiltrate of mononuclear cells in the upper dermis with only minimal changes in the epidermis [7]. Thus, systemic effects of circulating cytokines may play an important role in the induction of epidermal cell proliferation. It was proposed that in normal skin there could be an interaction between the epidermis and circulating T cells [8]. Recently, abnormal cytokines production is being studied as a possible mechanism in psoriasis.

Cytokines are small, biologically highly active proteins that regulate the growth, function, and differentiation of cells and help steer the immune response and inflammation [9]. Keratinocytes secrete a number of cytokines and chemokines that either activate or suppress immune responses [10]. However, precise mechanism of their involvement in psoriasis remains unclear. Any local or systemic stimulus may stimulate keratinocyte cytokines production [11]. The pattern of cytokine expression suggests that Th1 cells may mediate or maintain disease $[12,13,14]$. Our data confirmed previously published data that the Th1 cytokines (TNF- $\alpha$, IFN- $\gamma$, and IL12) and some proinflammatory cytokines (such as IL-6, IL-8, and IL-18) are influenced in the serum of psoriatic patients. Moreover, we found significant correlation between severity of the disease and serum levels of IFN- $\gamma$, IL-12, IL-17, and IL-18. Additionally, our data showed that serum levels of these cytokines did not correlate with age or gender.
The previous studies demonstrated a significant increase in IFN- $\gamma[15,16,17,18]$, TNF- $\alpha[19,20,21,22,23]$, IL-6 [19, 22, 24], IL-8 [15, 19, 23, 25, 26], and IL-18 [27] in the serum of psoriatic patients compared to the healthy controls. The exact role of TNF- $\alpha$ in the pathomechanism of psoriasis is still unclear, but anti-TNF- $\alpha$ therapy is highly effective in psoriasis indicating that this cytokine has, together with IFN- $\gamma$, a central role in the pathogenesis. IFN- $\gamma$ and TNF- $\alpha$ induce IL-6, IL-8, IL-12, and IL-18 and constitute an important link in the cytokine network in the pathogenesis of psoriasis [5]. Moreover, the intradermal administration of IFN- $\gamma$ into nonlesional skin of psoriatic patients causes the appearance of lesions at the inoculation site [10]. IL-6 mediates T-cell activation, stimulates proliferation of keratinocytes [28], and, at the beginning of acute inflammation, mediates the acute phase responses [29]. Elevated amounts of IL- 8 have been detected in psoriatic lesional skin [30]. Many studies indicate that IL- 8 may be involved in the pathomechanism of psoriasis. In fact, data currently available suggest that this cytokine exerts a critical role as a potent chemoattractant for neutrophils and T lymphocytes, as well as a factor prompting keratinocyte proliferation [10]. IL-12 plays a major role in the development of Th1-cell-mediated immune responses. Besides, in situ IL-12 may also have a role in the induction of new psoriatic skin lesions [31]. Contrary to our finding, Jacob et al reported that a serum mean IL-12 level was decreased in patients with psoriasis [15]. This different result may stem from the various laboratory methods used. We measured p40 subunit of IL-12. IL-12 and IL-23 are heterodimers that share a common p40 chain. Nevertheless, an antibody to the human IL-12/p40 (anti-IL-12p40) was reported to have significant effect in psoriatic patients [32]. IL-18 has an important role in cellular adhesion, being the final common pathway used by IL-1 and TNF- $\alpha$ that leads to ICAM-1 
(intercellular adhesion molecule 1) expression [33]. IL-18 receptor expression is upregulated by IL-12, and thereby these two cytokines synergize to stimulate IFN- $\gamma$ release $[34,35]$. IL-18 acts on dendritic cells synergistically with IL-12, which is also produced by the dendritic cells, thereby greatly increasing the IFN- $\gamma$ production [36]. The data support the important proinflammatory role of IFN$\gamma$ and TNF- $\alpha$ in the clinical manifestation of psoriasis. We could not conclude why high serum levels of TNF- $\alpha$ had no correlation with PASI scores in patients with psoriasis.

We did not find any study about serum levels of IL17 in psoriasis in the literature. Our results may be the first report on serum levels of IL-17 in patients with psoriasis. IL-17 expression could not be detected in normal skin, but was found in psoriatic lesional skin [37]. We found that serum IL-17 levels were slightly higher in psoriatic patients than controls, although not significant. IL17 , which is produced by activated CD4+ T cells, synergizes with IFN- $\gamma$ to enhance the production of proinflammatory cytokines by human keratinocytes, including IL-6 and IL-8, thereby increasing the migration of $\mathrm{T}$ cells to the skin. IL-17 can also be considered a proinflammatory cytokine. This effect of IL-17 is further potentiated when IFN- $\gamma$ is also present, and increase in IL- 6 and IL- 8 secretion can be observed after costimulation [38]. In vivo data in the biological role of IL-17 are even more limited [39]. It is not clear why we found IL-17 levels normal but it had a significant correlation with PASI in our psoriatic patients. Further new studies would be beneficial to confirm these results and to understand the pathogenesis of psoriasis in vivo.

Psoriasis can be described as a T-cell-mediated disease, with a complex role for a variety of cytokines and other factors. Interaction between $T$ lymphocytes and keratinocytes, via cytokines, is likely to play a pivotal role in the pathogenic process in psoriasis. The impact of this study is the significant correlation among high serum levels of IFN- $\gamma$, IL-12, and IL-18 in psoriatic patients. Similarly, Piskin et al showed that expressions of IFN- $\gamma$ inducers IL-12, IL-18, and IL-23 in lesional skin have decreased after narrowband ultraviolet-B therapy in psoriasis [41]. This finding indicates that the production of these cytokines, with similar biologic properties and activity spectra, may be strictly regulated by one another. How the synthesis of this complex array of cytokines is coordinated and regulated in vivo is an essential question for further work.

In the present study, serum TNF- $\alpha$, IFN- $\gamma$, IL-6, IL- 8 , IL-12, and IL-18 levels were significantly higher in the patients with psoriasis than in healthy controls. Cytokines play an important role in the pathogenesis of psoriasis. When cytokines levels are measured in serum, it is not possible to determine the origin of these cytokines. The serum cytokine concentrations are altered by several processes like the production, tissue/cellular deposition, degradation, and elimination of these molecules; furthermore other tissue sources of cytokine production might exist beside the circulating $\mathrm{T}$ cells. The origin of circulating cytokines in blood serum in psoriatic patients is not clear. To achieve the cytokine concentration that can induce biological responses at distant skin lesions, huge amounts of free cytokines that induce generalized inflammation are required. Thus, the receptors on psoriatic keratinocytes may be more sensitive to these cytokines. Furthermore, we demonstrated here that high levels of IFN- $\gamma$, IL-12, and IL-18 correlated with PASI and those measurements of serum levels of these cytokines may be an objective parameter for psoriasis activity and clinical severity. These data confirm the hypothesis that psoriasis might be considered as a true systemic disease with particular immunologic pathways. An array of these cytokines may be considered as useful follow-up markers for monitoring psoriatic patients and optimizing therapeutic strategies in daily medical practice. In addition, to measure these cytokines' levels in serum, if there is a doubt in skin histology, it would be more useful to differentiate psoriasis from other skin diseases, such as seborrheic dermatitis or parapsoriasis.

The importance of serum cytokines in dermatology is increasing dramatically. The new ELISA methods are useful with their high specificity and good standardizability against the high costs [40]. Unfortunately, the cytokine assay results may vary due to the methods used for cytokines detection and their sensitivities, interferences due to different drugs used, and the effect of concomitant pathologies [17]. The skin, largest organ of the body, is the site of more than 50 different clinically recognizable inflammatory dermatological diseases. Thus, the exact role of serum cytokines needs to be clarified and further studies are required in the pathogenesis of cutaneous disorders including psoriasis. However, the question remains whether cytokine abnormalities represent the egg or the chicken in dermatologic disorders. It appears likely that these changes are not the cause, but the consequence of, the dermatological diseases. Understanding the in vivo immunological cascade as described above is crucial for the development of biological therapies. Whether blocking these cytokine activities, either by antibodies or specific inhibitors, may open new therapeutic aspects has yet to be demonstrated $[42,43]$. Until other inflammatory skin diseases are studied, we cannot speculate on the specificity of these results, and further investigations will be required to define the role of serum proinflammatory cytokines in the pathogenesis and their correlation with clinical severity of psoriasis.

\section{REFERENCES}

[1] Lowes MA, Lew W, Krueger JG. Current concepts in the immunopathogenesis of psoriasis. Dermatol Clin. 2004;22(4):349-369.

[2] Bos JD, De Rie MA. The pathogenesis of psoriasis: immunological facts and speculations. Immunol Today. 1999;20(1):40-46. 
[3] Griffiths CEM. The immunological basis of psoriasis. J Eur Acad Dermatol Venereol. 2003;17(suppl 2):1-5.

[4] Chamian F, Krueger JG. Psoriasis vulgaris: an interplay of $\mathrm{T}$ lymphocytes, dendritic cells, and inflammatory cytokines in pathogenesis. Curr Opin Rheumatol. 2004;16(4):331-337.

[5] Gudjonsson JE, Johnston A, Sigmundsdottir H, Valdimarsson H. Immunopathogenic mechanisms in psoriasis. Clin Exp Immunol. 2004;135(1):1-8.

[6] Fry L. Psoriasis. Br J Dermatol. 1988;119(4):445-461.

[7] Lever WF, Schaumburg-Lever G. Histopathology of the Skin. Philadelphia, Pa: JB Lippincott; 1975:135146.

[8] McKenzie RC, Sauder DN. The role of keratinocyte cytokines in inflammation and immunity. J Invest Dermatol. 1990;95(suppl 6):105S-107S.

[9] Thomson A. The Cytokine Handbook. 3rd ed. New York, NY: Academic Press; 1998.

[10] Bonifati C, Ameglio F. Cytokines in psoriasis. Int J Dermatol. 1999;38(4):241-251.

[11] Nickoloff BJ, Karabin GD, Barker JN, et al. Cellular localization of interleukin-8 and its inducer, tumor necrosis factor-alpha in psoriasis. Am J Pathol. 1991;138(1):129-140.

[12] Prinz JC. Which T cells cause psoriasis? Clin Exp Dermatol. 1999;24(4):291-295.

[13] Uyemura K, Yamamura M, Fivenson DF, Modlin RL, Nickoloff BJ. The cytokine network in lesional and lesion-free psoriatic skin is characterized by a Thelper type 1 cell-mediated response. J Invest Dermatol. 1993;101(5):701-705.

[14] De Rie MA, Goedkoop AY, Bos JD. Overview of psoriasis. Dermatol Ther. 2004;17(5):341-349.

[15] Jacob SE, Nassiri M, Kerdel FA, Vincek V. Simultaneous measurement of multiple Th1 and Th2 serum cytokines in psoriasis and correlation with disease severity. Mediators Inflamm. 2003;12(5):309-313.

[16] El Barnawi NY, Giasuddin ASM, Ziu MM, Singh M. Serum cytokine levels in psoriasis vulgaris. $\mathrm{Br} J$ Biomed Sci. 2001;58(1):40-44.

[17] Szegedi A, Aleksza M, Gonda A, et al. Elevated rate of Thelper1 $(\mathrm{T}(\mathrm{H}) 1)$ lymphocytes and serum IFN- $\gamma$ levels in psoriatic patients. Immunol Lett. 2003;86(3):277-280.

[18] Gomi T, Shiohara T, Munakata T, Imanishi K, Nagashima $\mathrm{M}$. Interleukin $1 \alpha$, tumor necrosis factor $\alpha$, and interferon $\gamma$ in psoriasis. Arch Dermatol. 1991;127(6):827-830.

[19] Abanmi A, Al Harthi F, Al Agla R, Khan HA, Tariq M. Serum levels of proinflammatory cytokines in psoriasis patients from Saudi Arabia. Int J Dermatol. 2005;44(1):82-83.

[20] Mussi A, Bonifati C, Carducci M, et al. Serum TNFalpha levels correlate with disease severity and are reduced by effective therapy in plaque-type psoriasis. J Biol Regul Homeost Agents. 1997;11(3):115118.
[21] Chodorowska G. Plasma concentrations of IFNgamma and TNF-alpha in psoriatic patients before and after local treatment with dithranol ointment. J Eur Acad Dermatol Venereol. 1998;10(2):147151.

[22] Mizutani H, Ohmoto Y, Mizutani T, Murata M, Shimizu M. Role of increased production of monocytes TNF- $\alpha$, IL- $1 \beta$ and IL- 6 in psoriasis: relation to focal infection, disease activity and responses to treatments. J Dermatol Sci. 1997;14(2):145-153.

[23] Okubo Y, Koga M. Peripheral blood monocytes in psoriatic patients overproduce cytokines. J Dermatol Sci. 1998;17(3):223-232.

[24] Szepietowski JC, Bielicka E, Nockowski P, Noworolska A, Wasik F. Increased interleukin-7 levels in the sera of psoriatic patients: lack of correlations with interleukin-6 levels and disease intensity. Clin Exp Dermatol. 2000;25(8):643-647.

[25] Biasi D, Carletto A, Caramaschi P, et al. Neutrophil functions and IL-8 in psoriatic arthritis and in cutaneous psoriasis. Inflammation. 1998;22(5):533543.

[26] Pietrzak A, Koziol-Montewka M, Lecewicz-Torun B, Krasowska D. Is there any correlation between the total number of neutrophils in plasma and concentration of interleukin- 8 in psoriatic patients? Med Sci Monit. 2000;6(5):867-870.

[27] Gangemi S, Merendino RA, Guarneri F, et al. Serum levels of interleukin-18 and s-ICAM-1 in patients affected by psoriasis: preliminary considerations. J Eur Acad Dermatol Venereol. 2003;17(1):42-46.

[28] Sehgal PB. Interleukin-6: molecular pathophysiology. J Invest Dermatol. 1990;94(suppl 6):2S-6S.

[29] Ishihara K, Hirano T. IL-6 in autoimmune disease and chronic inflammatory proliferative disease. $C y$ tokine Growth Factor Rev. 2002;13(4-5):357-368.

[30] Sticherling M, Sautier W, Schroder JM, Christophers E. Interleukin-8 plays its role at local level in psoriasis vulgaris. Acta Derm Venereol. 1999;79(1):4-8.

[31] Yawalkar N, Karlen S, Hunger R, Brand CU, Braathen LR. Expression of interleukin-12 is increased in psoriatic skin. J Invest Dermatol. 1998;111(6):10531057.

[32] Kauffman CL, Aria N, Toichi E, et al. A phase I study evaluating the safety, pharmacokinetics, and clinical response of a human IL-12 p40 antibody in subjects with plaque psoriasis. J Invest Dermatol. 2004;123(6):1037-1044.

[33] Borish LC, Steinke JW. Cytokines and chemokines. J Allergy Clin Immunol. 2003;111(suppl 2):S460-S475.

[34] Yoshimoto T, Takeda K, Tanaka T, et al. IL-12 upregulates IL-18 receptor expression on T cells, Th1 cells, and B cells: synergism with IL-18 for IFN- $\gamma$ production. J Immunol. 1998;161(7):3400-3407.

[35] Fantuzzi G, Reed DA, Dinarello CA. IL-12-induced IFN-gamma is dependent on caspase-1 processing of the IL-18 precursor. J Clin Invest. 1999;104(6):761767. 
[36] Dinarello CA. IL-18: a TH1-inducing, proinflammatory cytokine and new member of the IL-1 family. $J$ Allergy Clin Immunol. 1999;103(1 pt 1):11-24.

[37] Witowski J, Ksiazek K, Jorres A. Interleukin-17: a mediator of inflammatory responses. Cell Mol Life Sci. 2004;61(5):567-579.

[38] Teunissen MBM, Koomen CW, de Waal Malefyt R, Wierenga EA, Bos JD. Interleukin-17 and interferon$\gamma$ synergize in the enhancement of proinflammatory cytokine production by human keratinocytes. J Invest Dermatol. 1998;111(4):645-649.

[39] Spriggs MK. Interleukin-17 and its receptor. J Clin Immunol. 1997;17(5):366-369.

[40] Piskin G, Tursen U, Sylva-Steenland RMR, Bos JD, Teunissen MB. Clinical improvement in chronic plaque-type psoriasis lesions after narrow-band UVB therapy is accompanied by a decrease in the expression of IFN- $\gamma$ inducers-IL-12, IL-18 and IL-23. Exp Dermatol. 2004;13(12):764-772.

[41] Asadullah K, Sterry W, Volk HD. Analysis of cytokine expression in dermatology. Arch Dermatol. 2002;138(9):1189-1196.

[42] Williams JDL, Griffiths CEM. Cytokine blocking agents in dermatology. Clin Exp Dermatol. 2002;27(7):585-590.

[43] Gottlieb AB. Psoriasis: emerging therapeutic strategies. Nat Rev Drug Discov. 2005;4(1):19-34. 


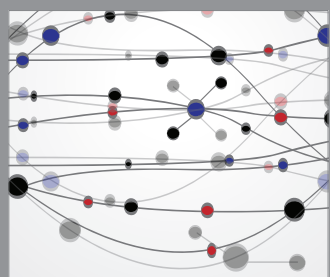

The Scientific World Journal
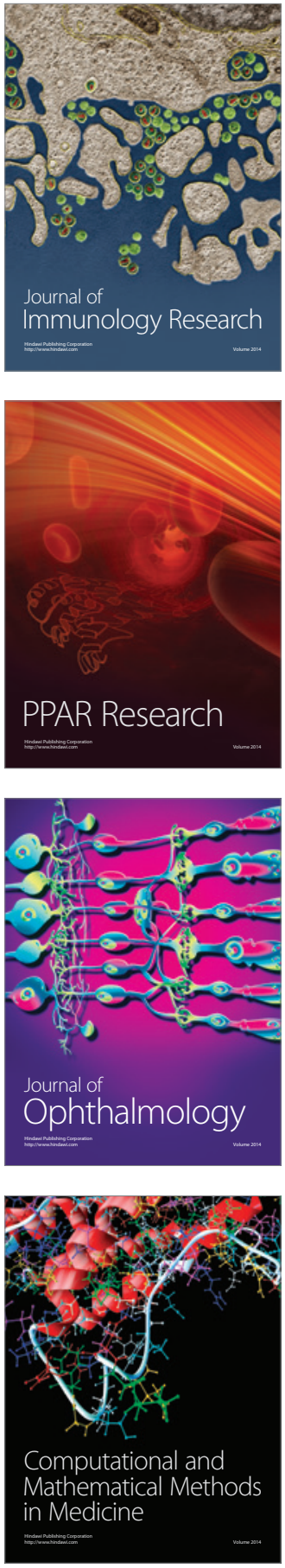

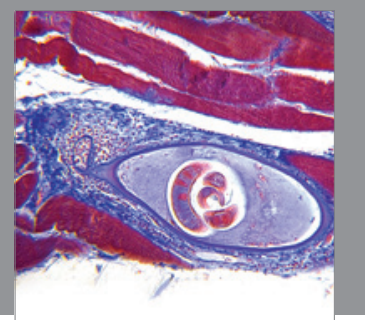

Gastroenterology

Research and Practice
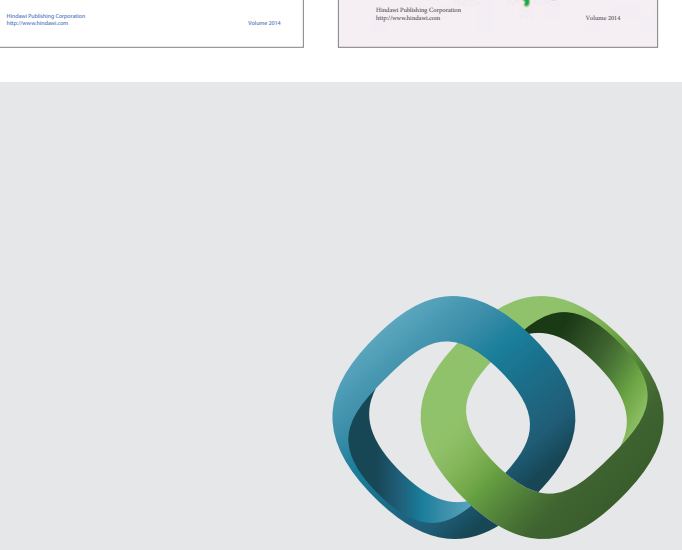

\section{Hindawi}

Submit your manuscripts at

http://www.hindawi.com
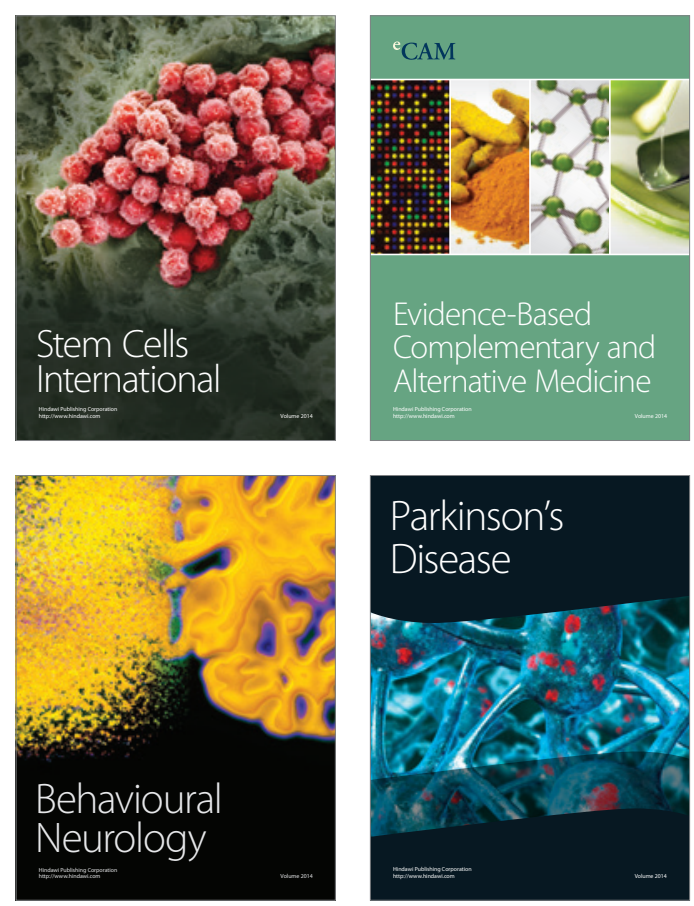

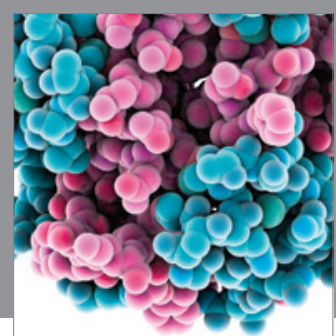

Journal of
Diabetes Research

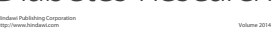

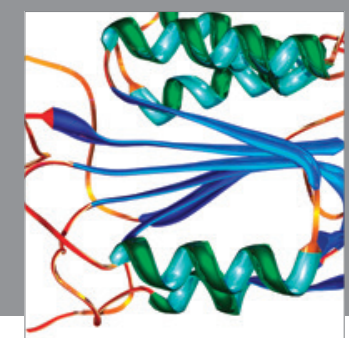

Disease Markers
